\title{
Parameters in finding why common people become Followers of Self Declared Godman by the use of Rough Set Theory
}

\author{
Sujogya Mishra \\ Research scholar \\ Utkal University \\ Bhubaneswar-751004, India
}

\author{
Shakti Prasad Mohanty \\ Department of Mathematics \\ College of Engineering and \\ Technology \\ Bhubaneswar-751003, India
}

\author{
Sateesh Kumar Pradhan \\ Department of Computer \\ Science \\ Utkal University \\ Bhubaneswar-751004, India
}

\author{
Radhanath Hota \\ Department of Computer Science \\ Orissa University of Agriculture \& Techonology \\ Bhubaneswar-751003, India
}

\begin{abstract}
This paper conceived looking at present scenario of our country(INDIA),Job scarcity, financial crisis of middleclass people deliver self declared god man our intention is very clear that we don't want to hurt any body's sentiments.We just apply mathematical tools
\end{abstract}

On the data which collect from various sources

\section{Keywords}

Rough Set Theory, related data, regarding terrorism Granular computing, Data mining

\section{INTRODUCTION}

The growth of information and number of existing databases are far exceeds the ability of common people to analyze it. Which creates a needs to ex-tract knowledge from databases[1] data regarding blind belief is so high that it's databases has accumulated large volume of information. In the present scenario intelligent method[2] means data analysis based upon strong assumptions knowledge about dependencies, probability distributions and large number of experiments which unable to derive conclusions from incomplete knowledge, or cannot proceed further with the inconsistent pieces of information. The standard intelligent method available for data analysis are neural network[3] Bayesian classifier [4] genetic algorithms[5] decision trees [6] fuzzy set [7] . Rough set theory, Professor Z. Pawlak [8] .The theory of rough sets is a mathematical tool for deriving inference from un-certain and incomplete data base information. The rough set reduction algorithms contribute to approximate the decision classes using possibly large and simplified patterns [9]. Dempster-Shafer theory or statistical methods, rough set analysis requires no external parameters and uses only those information present in the given data [10].In this paper we discusses how rough set theory is useful in analyzing large data collected from different sources, and for generating classification rules from a set of observed samples of the common people. Using rough set reduction technique we find all reducts of the data which contains the minimal subset of attributes that are associated with a class label for classification. This paper is organized in the following manner $1^{\text {st }}$ section contains the literature review $2^{\text {nd }}$ section deals with data analysis. Which we collected from various sources and $3^{\text {rd }}$ section contains the algorithm, conclusion and statistical validation present in the $4^{\text {th }}$ section.

The growth of data size and number of existing databases are far exceeds the ability of humans to analyze it. Which creates an urge to ex-tract knowledge from databases[1] data regarding terrorism is so high that it's databases has accumulated large volume of information. In the present scenario intelligent method[2] means data analysis based upon strong assumptions knowledge about dependencies, probability distributions and large number of experiments which unable to derive conclusions from incomplete knowledge, or cannot proceed further with the inconsistent pieces of information. The standard intelligent method available for data analysis are neural network[3] Bayesian classifier [4] genetic algorithms[5] decision trees [6] fuzzy set [7] . Rough set theory, Professor Z. Pawlak [8] .The theory of rough sets is a mathematical tool for deriving inference from un-certain and incomplete data base information. The rough set reduction algorithms contribute to approximate the decision classes using possibly large and simplified patterns [9]. Dempster-Shafer theory or statistical methods, rough set analysis requires no external parameters and uses only those information present in the given data [10].In this paper we discusses how rough set theory is useful in analyzing large data collected from different sources, and for generating classification rules from a set of observed samples of the common people. Using rough set reduction technique we find all reducts of the data which contains the minimal subset of attributes that are associated with a class label for classification. This paper is organized in the following manner $1^{\text {st }}$ section contains the literature review $2^{\text {nd }}$ section deals with data analysis. Which we collected from various sources and $3^{\text {rd }}$ section contains the algorithm and rule generation for classification and statistical validation the $4^{\text {th }}$ section contains the conclusion part and the future work. 


\section{PRILIMINARIES}

\subsection{Rough set}

Rough set theory as introduced by Z. Pawlak[8] is an extension of conventional set theory that support approximations in decision making.

\subsubsection{Approximation Space: An Approximation} space is a pair $(\mathrm{U}, \mathrm{R})$ where $\mathrm{U}$ is a non empty finite set called the universe $\mathrm{R}$ is an equivalence relation defined on U.

2.1.2 Information System: An information system is a pair $\mathrm{S}=(\mathrm{U}, \mathrm{A})$, where $\mathrm{U}$ is thenon-empty finite set called the universe, $\mathrm{A}$ is the non-empty finite set of attributes.

2.1.3 Decision Table: A decision table is a special case of information systems $\mathrm{S}=(\mathrm{U}, \mathrm{A}=\mathrm{C} \mathrm{U}\{\mathrm{d}\})$, where $\mathrm{d}$ is not in $\mathrm{C}$. Attributes in $\mathrm{C}$ are called conditional attributes and $\mathrm{d}$ is a designated attribute called the decision attribute.

2.1.4 Approximations of Sets: Let $\mathrm{S}=(\mathrm{U}, \mathrm{R})$ be an approximation space and $\mathrm{X}$ be a subset of U.The lower

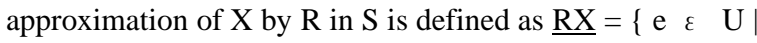
[e] $\varepsilon \quad X\}$ and The upper approximation of $X$ by $R$ in $S$ is defined as $\overline{R X}=\{e \in U /[e] \cap X \neq \phi\}$ where [e] denotes the equivalence class containing e. A subset $\mathrm{X}$ of $\mathrm{U}$ is said to be $\mathrm{R}$-definable in $\mathrm{S}$ if and only if $\overline{R X}=\underline{\mathrm{RX}}$. A set $\mathrm{X}$ is rough in $\mathrm{S}$ if its boundary set is nonempty.

\subsection{Reduct and Core}

Let $\mathrm{S}=(\mathrm{U}, \mathrm{A}=\mathrm{C} \mathrm{U} \mathrm{D})$ be a decision table. A subset $\mathrm{R}$ of $\mathrm{C}$ is a reduct of $C$, if $\operatorname{POS}_{\mathbf{R}}(\mathrm{D})=\operatorname{POS}_{\mathrm{C}}(\mathrm{D})$ and $\mathrm{S}^{\prime}=(\mathrm{U}, \mathrm{RUD})$ is independent, ie., all attributes in $\mathrm{R}$ are indispensible in S'. Core of $\mathrm{C}$ is the set of attributes shared by all reducts of C. $\operatorname{CORE}(\mathrm{C})=\cap \operatorname{RED}(\mathrm{C})$ where, $\operatorname{RED}(\mathrm{C})$ is the set of all reducts of $\mathrm{C}$. The reduct is often used in the attribute selection process to eliminate redundant attributes towards decision making.

\subsection{Correlation}

Correlation define as a mutual relationship or connection between two or more things .The quantity $r$, called the linear correlation coefficient, measures the strength and the direction of a linear relationship between two variables. The linear correlation coefficient is sometimes referred to as the Pearson product moment correlation coefficient in honor of its developer Karl Pearson. The mathematical formula for its coefficient given by the formula.

$$
r=\frac{n \sum x y-\left(\sum x\right)\left(\sum y\right)}{\sqrt{n\left(\sum x^{2}\right)-\left(\sum x\right)^{2}} \sqrt{n\left(\sum y^{2}\right)-\left(\sum y\right)^{2}}}
$$

\subsection{Different types of error-}

1) Type 1 error-Rejecting a hypothesis even though it is true

2) Type 2 error-Accepting the hypothesis when it is false

3) Type 3 error-Rejecting a hypothesis correctly for wrong reason

\section{BASIC IDEA}

Basic idea for the proposed work is conceived from very general blind faith or belief of the society. We initially consider 1000 samples, of very common people and seven conditional attributes such as financial crisis , lack of education, ,to achieve goal in very short period of time , life below poverty lines, socially neglected, minority, family background it's values are defined as average ,above average and high and decision attributes are positive, negative . For better understanding we rename the attributes as $\left(\mathrm{a}_{1}, \mathrm{a}_{2}, \mathrm{a}_{3}, \mathrm{a}_{4}, \mathrm{a}_{5} \mathrm{a}_{6}, \mathrm{a}_{7}\right)$ as conditional attributes ,$\left(b_{1}, b_{2}, b_{3}\right)$ as values of the conditional attributes and $\left(c_{1}, c_{2}\right)$ as decision attributes respectively We collected the data for our from different sources

\section{DATA REDUCTION}

Approximation: The starting point of rough set theory is the indiscernibility relation, generated by information concerning objects of interest. The indiscernibility relation is intended to express the fact that due to the lack of knowledge it is unable to discern some objects employing the available information Approximations is also other an important concept in Rough Sets Theory, being associated with the meaning of the approximations topological operations ( $\mathrm{Wu}$ et al., 2004). The lower and the upper approximations of a set are interior and closure operations in a topology generated by the indiscernibility relation. Below is presented and described the types of approximations that are used in Rough Sets Theory.

a. Lower Approximation: Lower Approximation is a description of the domain objects that are known with certainty to belong to the subset of interest.The Lower Approximation Set of a set $\mathrm{X}$, with regard to $\mathrm{R}$ is the set of all objects, which can be classified with $\mathrm{X}$ regarding $\mathrm{R}$, that is denoted as $R_{L}$

b. Upper approximation: Upper Approximation is a description of the objects that possibly belong to the subset of interest. The Upper Approximation Set of a set X regarding $\mathrm{R}$ is the set of all of objects which can be possibly classified with $\mathrm{X}$ regarding $\mathrm{R}$. Denoted as $\mathrm{R}_{\mathrm{U}}$

c. Boundary Region (BR): Boundary Region is description of the objects that of a set $\mathrm{X}$ regarding $\mathrm{R}$ is the set of all the objects, which cannot be classified neither as $\mathrm{X}$ nor $-\mathrm{X}$ regarding $R$. If the boundary region $X=\phi$ then the set is considered "Crisp", that is, exact in relation to $\mathrm{R}$; otherwise, if the boundary region is a set $\mathbf{X} \neq \phi$ the set $\mathrm{X}$ "Rough" is considered. In that the boundary region is BR = $\mathrm{R}_{\mathrm{U}}-\mathrm{R}_{\mathrm{L}}$

Application and analysis on the data set and rule generation being presented in the following tables. Table -1 is the initial table, and the process of analysis is present in the subsequent tables. 
Table-1

\begin{tabular}{|c|c|c|c|c|c|c|c|c|}
\hline $\mathbf{E}$ & $\mathbf{a}_{1}$ & $\mathbf{a}_{2}$ & $\mathbf{a}_{3}$ & $\mathbf{a}_{4}$ & $a_{5}$ & $\mathbf{a}_{6}$ & $\mathbf{a}_{7}$ & d \\
\hline $\mathrm{E}_{1}$ & $\mathrm{~b}_{2}$ & $\mathrm{~b}_{2}$ & $b_{1}$ & $\mathrm{~b}_{1}$ & $\mathrm{~b}_{1}$ & $\mathrm{~b}_{2}$ & $\mathrm{~b}_{1}$ & $\mathrm{c}_{2}$ \\
\hline $\mathrm{E}_{2}$ & $\mathrm{~b}_{2}$ & $\mathrm{~b}_{2}$ & $b_{1}$ & $b_{3}$ & $b_{3}$ & $\mathrm{~b}_{2}$ & $b_{2}$ & $\mathrm{c}_{2}$ \\
\hline $\mathrm{E}_{3}$ & $b_{1}$ & $\mathrm{~b}_{2}$ & $\mathrm{~b}_{2}$ & $b_{3}$ & $b_{3}$ & $\mathrm{~b}_{1}$ & $\mathrm{~b}_{2}$ & $\mathrm{c}_{1}$ \\
\hline $\mathrm{E}_{4}$ & $\mathrm{~b}_{1}$ & $\mathrm{~b}_{2}$ & $\mathrm{~b}_{2}$ & $b_{3}$ & $b_{3}$ & $b_{1}$ & $b_{2}$ & $\mathrm{c}_{1}$ \\
\hline $\mathrm{E}_{5}$ & $b_{3}$ & $b_{3}$ & $b_{3}$ & $b_{3}$ & $b_{2}$ & $b_{3}$ & $\mathrm{~b}_{2}$ & $\mathrm{c}_{2}$ \\
\hline $\mathrm{E}_{6}$ & $b_{1}$ & $b_{2}$ & $\mathrm{~b}_{2}$ & $b_{2}$ & $\mathrm{~b}_{2}$ & $\mathrm{~b}_{1}$ & $\mathrm{~b}_{2}$ & $c_{2}$ \\
\hline $\mathrm{E}_{7}$ & $b_{2}$ & $b_{2}$ & $b_{2}$ & $\mathrm{~b}_{2}$ & $\mathrm{~b}_{2}$ & $\mathrm{~b}_{2}$ & $b_{2}$ & $\mathrm{c}_{1}$ \\
\hline $\mathrm{E}_{8}$ & $b_{1}$ & $b_{1}$ & $b_{1}$ & $b_{1}$ & $\mathrm{~b}_{1}$ & $b_{1}$ & $b_{1}$ & $c_{2}$ \\
\hline$\overline{E_{9}}$ & $\mathrm{~b}_{1}$ & $\mathrm{~b}_{2}$ & $b_{2}$ & $b_{3}$ & $\mathrm{~b}_{3}$ & $b_{1}$ & $b_{3}$ & $\mathrm{c}_{1}$ \\
\hline $\mathrm{E}_{10}$ & $b_{1}$ & $\mathrm{~b}_{2}$ & $b_{2}$ & $\mathrm{~b}_{2}$ & $\mathrm{~b}_{2}$ & $\mathrm{~b}_{1}$ & $\mathrm{~b}_{2}$ & $\mathrm{c}_{2}$ \\
\hline $\mathrm{E}_{11}$ & $b_{2}$ & $b_{3}$ & $b_{3}$ & $b_{3}$ & $\mathrm{~b}_{3}$ & $\mathrm{~b}_{2}$ & $\mathrm{~b}_{2}$ & $\mathrm{c}_{1}$ \\
\hline $\mathrm{E}_{12}$ & $b_{1}$ & $b_{2}$ & $b_{3}$ & $b_{1}$ & $b_{2}$ & $\mathrm{~b}_{1}$ & $\mathrm{~b}_{2}$ & $\mathrm{c}_{1}$ \\
\hline $\mathrm{E}_{13}$ & $b_{3}$ & $\mathrm{~b}_{2}$ & $\mathrm{~b}_{2}$ & $\mathrm{~b}_{2}$ & $b_{1}$ & $b_{3}$ & $b_{1}$ & $c_{2}$ \\
\hline $\mathrm{E}_{14}$ & $b_{3}$ & $b_{3}$ & $b_{3}$ & $b_{3}$ & $b_{3}$ & $\mathrm{~b}_{3}$ & $b_{3}$ & $\mathrm{c}_{1}$ \\
\hline $\mathrm{E}_{15}$ & $b_{1}$ & $b_{1}$ & $b_{1}$ & $\mathrm{~b}_{1}$ & $b_{1}$ & $\mathrm{~b}_{1}$ & $b_{1}$ & $\mathrm{c}_{2}$ \\
\hline $\mathrm{E}_{16}$ & $b_{1}$ & $b_{1}$ & $b_{1}$ & $\mathrm{~b}_{1}$ & $\mathrm{~b}_{1}$ & $\mathrm{~b}_{1}$ & $\mathrm{~b}_{1}$ & $c_{2}$ \\
\hline $\mathrm{E}_{17}$ & $b_{1}$ & $b_{3}$ & $b_{2}$ & $\mathrm{~b}_{2}$ & $\mathrm{~b}_{3}$ & $\mathrm{~b}_{1}$ & $\mathrm{~b}_{3}$ & $\mathrm{c}_{1}$ \\
\hline $\mathrm{E}_{18}$ & $\mathrm{~b}_{1}$ & $\mathrm{~b}_{2}$ & $\mathrm{~b}_{2}$ & $\mathrm{~b}_{3}$ & $\mathrm{~b}_{2}$ & $\mathrm{~b}_{1}$ & $\mathrm{~b}_{2}$ & $\overline{c_{2}}$ \\
\hline $\mathrm{E}_{19}$ & $b_{1}$ & $b_{3}$ & $\mathrm{~b}_{1}$ & $b_{3}$ & $\mathrm{~b}_{3}$ & $\mathrm{~b}_{1}$ & $b_{3}$ & $\mathrm{c}_{2}$ \\
\hline $\mathrm{E}_{20}$ & $b_{1}$ & $b_{3}$ & $b_{1}$ & $b_{3}$ & $b_{3}$ & $b_{1}$ & $b_{3}$ & $\mathrm{c}_{1}$ \\
\hline
\end{tabular}

The decision table -1 , takes the initial values before finding the reduct looking at the data table it is found that entities $E_{15}, E_{16}$, are same so keep one record either from $E_{15}$ or $\mathrm{E}_{16}$ similarly $\mathrm{E}_{3} \mathrm{E}_{4}$ has same value so we keep one record either from $E_{3}$ or $E_{4}$ in the next table. $E_{19}$ and $E_{20}$ ambiguous in nature so we drop both from next table, that is table-2

Reduced Table-2 from table-1

\begin{tabular}{|l|l|l|l|l|l|l|l|}
\hline $\mathbf{E}$ & $\mathbf{a}_{1}$ & $\mathbf{a}_{2}$ & $\mathbf{a}_{3}$ & $\mathbf{a}_{4}$ & $\mathbf{a}_{5}$ & $\mathbf{a}_{7}$ & $\mathbf{D}$ \\
\hline $\mathrm{E}_{1}$ & $\mathrm{~b}_{2}$ & $\mathrm{~b}_{2}$ & $\mathrm{~b}_{1}$ & $\mathrm{~b}_{1}$ & $\mathrm{~b}_{1}$ & $\mathrm{~b}_{1}$ & $\mathrm{c}_{2}$ \\
\hline $\mathrm{E}_{2}$ & $\mathrm{~b}_{2}$ & $\mathrm{~b}_{2}$ & $\mathrm{~b}_{1}$ & $\mathrm{~b}_{3}$ & $\mathrm{~b}_{3}$ & $\mathrm{~b}_{2}$ & $\mathrm{c}_{2}$ \\
\hline $\mathrm{E}_{4}$ & $\mathrm{~b}_{1}$ & $\mathrm{~b}_{2}$ & $\mathrm{~b}_{2}$ & $\mathrm{~b}_{3}$ & $\mathrm{~b}_{3}$ & $\mathrm{~b}_{2}$ & $\mathrm{c}_{1}$ \\
\hline
\end{tabular}

\begin{tabular}{|l|l|l|l|l|l|l|l|}
\hline$E_{5}$ & $b_{3}$ & $b_{3}$ & $b_{3}$ & $b_{3}$ & $b_{2}$ & $b_{2}$ & $c_{1}$ \\
\hline$E_{6}$ & $b_{1}$ & $b_{2}$ & $b_{2}$ & $b_{2}$ & $b_{2}$ & $b_{2}$ & $c_{2}$ \\
\hline$E_{7}$ & $b_{2}$ & $b_{2}$ & $b_{2}$ & $b_{2}$ & $b_{2}$ & $b_{2}$ & $c_{1}$ \\
\hline$E_{8}$ & $b_{1}$ & $b_{1}$ & $b_{1}$ & $b_{1}$ & $b_{1}$ & $b_{1}$ & $c_{2}$ \\
\hline$E_{9}$ & $b_{1}$ & $b_{2}$ & $b_{2}$ & $b_{3}$ & $b_{3}$ & $b_{3}$ & $c_{1}$ \\
\hline$E_{10}$ & $b_{1}$ & $b_{2}$ & $b_{2}$ & $b_{2}$ & $b_{2}$ & $b_{2}$ & $c_{2}$ \\
\hline$E_{11}$ & $b_{2}$ & $b_{3}$ & $b_{3}$ & $b_{3}$ & $b_{3}$ & $b_{2}$ & $c_{1}$ \\
\hline$E_{12}$ & $b_{1}$ & $b_{2}$ & $b_{3}$ & $b_{1}$ & $b_{2}$ & $b_{2}$ & $c_{1}$ \\
\hline$E_{13}$ & $b_{3}$ & $b_{2}$ & $b_{2}$ & $b_{2}$ & $b_{1}$ & $b_{1}$ & $c_{2}$ \\
\hline$E_{14}$ & $b_{3}$ & $b_{3}$ & $b_{3}$ & $b_{3}$ & $b_{3}$ & $b_{3}$ & $c_{1}$ \\
\hline$E_{15}$ & $b_{2}$ & $b_{1}$ & $b_{1}$ & $b_{1}$ & $b_{1}$ & $b_{1}$ & $c_{2}$ \\
\hline$E_{17}$ & $b_{1}$ & $b_{3}$ & $b_{2}$ & $b_{2}$ & $b_{3}$ & $b_{3}$ & $c_{1}$ \\
\hline$E_{18}$ & $b_{1}$ & $b_{2}$ & $b_{2}$ & $b_{3}$ & $b_{2}$ & $b_{2}$ & $c_{2}$ \\
\hline
\end{tabular}

$\mathrm{E}_{\text {high }}=\left\{\mathrm{E}_{4}, \mathrm{E}_{5}, \mathrm{E}_{7}, \mathrm{E}_{9}, \mathrm{E}_{11}, \mathrm{E}_{12}, \mathrm{E}_{14}, \mathrm{E}_{17}\right\}$

$E_{\text {average }}=\left\{E_{1}, E_{2}, E_{6}, E_{8}, E_{10}, E_{13}, E_{15}, E_{18}\right\}$

$\mathrm{E}\left(\mathrm{a}_{1}\right)_{\text {average }}=\left\{\mathrm{E}_{4}, \quad \mathrm{E}_{6}, \quad \mathrm{E}_{8}, \quad \mathrm{E}_{9}, \quad \mathrm{E}_{10}, \quad \mathrm{E}_{12}, \quad \mathrm{E}_{17}\right.$, $\left.\mathrm{E}_{18}\right\} \ldots \ldots \ldots \ldots(3)$

$\mathrm{E}\left(\mathrm{a}_{1}\right)$ aboveaverage $=\left\{\mathrm{E}_{1}, \mathrm{E}_{2}, \mathrm{E}_{7}, \mathrm{E}_{11}, \mathrm{E}_{15}\right\}$

$\mathrm{E}\left(\mathrm{a}_{1}\right)_{\text {high }}=\left\{\mathrm{E}_{5}, \mathrm{E}_{13}, \mathrm{E}_{14}\right\}$

The above result when compared with the high cases $\mathrm{E}\left(\mathrm{a}_{1}\right)_{\text {high }}$ strength[11] positive found to be $2 / 3$ about $66 \%$ where as for average cases of positive $E\left(a_{1}\right)_{\text {laverage }}$ is $1 / 2$ about $50 \%$ strength[11] $1 / 3$, so we arrive at a contradiction that we have $66 \%$ high positive cases and $50 \%$ average positive cases and almost $50 \%$ above average cases positive cases so for that $a_{1}$ doesn't provide any significance similarly

$E\left(a_{2}\right)_{\text {average }}($ negative $)=\left\{E_{8}, E_{15}\right\}$

$\mathrm{E}\left(\mathrm{a}_{2}\right)_{\text {aboveaverage }}$ (negative $)=\{$

$\left.\mathrm{E}_{4}, \mathrm{E}_{6}, \mathrm{E}_{7}, \mathrm{E}_{9}, \mathrm{E}_{10}, \mathrm{E}_{12}, \mathrm{E}_{13}, \mathrm{E}_{18}\right\} \ldots . .(7)$

$\mathrm{E}_{1}$,

$\mathrm{E}_{2}$,

$\mathrm{E}\left(\mathrm{a}_{2}\right)_{\text {high }}($ positive $)=\left\{\mathrm{E}_{5}, \mathrm{E}_{11}, \mathrm{E}_{17}\right\} \ldots$

Similar analysis strength[11] high $\mathrm{a}_{2}$ will be $4 / 4=1$ about cent percent of positive result And for strength[11] for average $a_{2}$ negative will be also $3 / 3=1$ about cent percent this attributes provide us a strong conclusion regarding the attribute $\mathrm{a}_{2}$, as both cases positive high and average negative result is about cent percent. So this is an important attribute for further classification now similarly for $\mathrm{a}_{3}$.

$\mathrm{E}\left(\mathrm{a}_{3}\right)_{\text {average }}$ (negative $)=\left\{\mathrm{E}_{1}, \mathrm{E}_{2}, \mathrm{E}_{8}, \mathrm{E}_{15}\right\}$.

$\mathrm{E}\left(\mathrm{a}_{3}\right)_{\text {aboveaverage }}=\left\{\mathrm{E}_{4}, \mathrm{E}_{6}, \mathrm{E}_{7}, \mathrm{E}_{9}, \mathrm{E}_{10}, \mathrm{E}_{13}, \mathrm{E}_{17}, \mathrm{E}_{18}\right\} \ldots$

$\mathrm{E}\left(\mathrm{a}_{3}\right)_{\text {high }}($ positive $)=\left\{\mathrm{E}_{5}, \mathrm{E}_{11}, \mathrm{E}_{12}\right\} \ldots$ 1)

Finding the strength [11] high $a_{3}$ high cases will be $4 / 4=1$ 
that is about cent percent and similarly for strength [11] for average $a_{3}$ cases will be gives negative result will be of $4 / 5$ about $80 \%$ negative cases for this reason we are considering the above average cases for classification and get a conclusion that $\mathrm{a}_{3}$ is an important attribute for further classification now similarly for $\mathrm{a}_{4}$ cases we consider the

$\mathrm{E}\left(\mathrm{a}_{4}\right)_{\text {average }}$ (negative $)=$

$\left\{\mathrm{E}_{1}, \mathrm{E}_{8}, \mathrm{E}_{12}, \mathrm{E}_{15}\right\}$

$\mathrm{E}\left(\mathrm{a}_{4}\right)_{\text {aboveaverage }}=\left\{\mathrm{E}_{6}, \mathrm{E}_{7}, \mathrm{E}_{10}, \mathrm{E}_{13}, \mathrm{E}_{17}\right\}$

$\mathrm{E}\left(\mathrm{a}_{4}\right)_{\text {high }}=\left\{\mathrm{E}_{2}, \mathrm{E}_{4}, \mathrm{E}_{5}, \mathrm{E}_{9}, \mathrm{E}_{11}, \mathrm{E}_{14}, \mathrm{E}_{18}\right\}$

Analyzing $\mathrm{a}_{4} \mathrm{E}\left(\mathrm{a}_{4}\right)_{\text {laverage }}$ negative strength[11] will be $4 / 5$ that is about $80 \%$ similarly for $\mathrm{E}\left(\mathrm{a}_{4}\right)_{\text {high }}$ positive strength[11] cases will be about 5/7 about 70\% now considering $\mathrm{a}_{5}$

$\mathrm{E}\left(\mathrm{a}_{5}\right)_{\text {average }}=\left\{\mathrm{E}_{1}, \mathrm{E}_{8}, \mathrm{E}_{13}, \mathrm{E}_{15}\right\}$

$\mathrm{E}\left(\mathrm{a}_{5}\right)_{\text {aboveaverage }}=\left\{\mathrm{E}_{5}, \mathrm{E}_{6}, \mathrm{E}_{7}, \mathrm{E}_{10}, \mathrm{E}_{12}, \mathrm{E}_{18}\right\}$

$\mathrm{E}\left(\mathrm{a}_{5}\right)_{\text {high }}=\left\{\mathrm{E}_{2}, \mathrm{E}_{3}, \mathrm{E}_{9}, \mathrm{E}_{11}, \mathrm{E}_{14}, \mathrm{E}_{17}\right\}$

$E\left(a_{5}\right)_{\text {average }}$ strength[11] for negative case will be $4 / 4$ about cent percent and $\mathrm{E}\left(\mathrm{a}_{5}\right)_{\text {high }}$ strength for positive $4 / 6$ about $66 \%$ positive strength[11] above average case given by $3 / 8$ about $37 \%$ so after analyzing the above data by strength view point we ignore attribute $a_{1}$ and $a_{5}$ as in $a_{1}$ strength [11] for low negative case is $100 \%$ high positive strength[11] $a_{1}$ about $20 \%$ similar argument in case of $a_{5}$ observing it's strength[11] now upon analyzing $a_{6}$ it has the following information

$\mathrm{E}\left(\mathrm{a}_{6}\right)_{\text {laverage }}=\left\{\quad \mathrm{E}_{4}, \quad \mathrm{E}_{6}, \quad \mathrm{E}_{8}, \quad \mathrm{E}_{9}, \quad \mathrm{E}_{10}, \quad \mathrm{E}_{12}, \quad \mathrm{E}_{17}\right.$, $\left.\mathrm{E}_{18}\right\} \ldots \ldots \ldots \ldots(18)$

$\mathrm{E}\left(\mathrm{a}_{6}\right)_{\text {aboveaverage }}=\left\{\mathrm{E}_{1}, \mathrm{E}_{2}, \mathrm{E}_{7}, \mathrm{E}_{11}, \mathrm{E}_{15}\right\}$

$\mathrm{E}\left(\mathrm{a}_{6}\right)_{\text {high }}=\left\{\mathrm{E}_{5}, \mathrm{E}_{13}, \mathrm{E}_{14}\right\}$

Provide the following strength cases $\mathrm{E}\left(\mathrm{a}_{6}\right)_{\text {high }}$ strength[11] found to be $2 / 3$ about $66 \%$ where as for negative cases of $\mathrm{E}\left(\mathrm{a}_{6}\right)_{\text {average }}$ is $1 / 2$ about $50 \%$ strength[11] $1 / 3$ cent percent similarly for negative cases of aboveaverage $E\left(a_{6}\right)$ strength[11] gives rise to be $3 / 5$ about $60 \%$, so we arrive at a contradiction that we have $66 \%$ positive and $50 \%$ negative and $60 \%$ negative case in moderate case of $a_{6}$ doesn't provide any significance similarly in case of $a_{7}$ there is peculiar case arises that above average cases of $a_{7}$ provide both positive and negative result so we arrive at an ambiguity, that's why we don't analyze $\mathrm{a}_{7}$ further

In table-3 we drop $a_{1}, a_{5}, a_{7}$. So after dropping $a_{1}, a_{5}$, and $a_{7}$ from table 2 we have the new reduct table, named as table3.

Reduced Table-3 from Table-2

\begin{tabular}{|l|l|l|l|l|}
\hline $\mathbf{E}$ & $\mathbf{a}_{2}$ & $\mathbf{a}_{3}$ & $\mathbf{a}_{4}$ & $\mathbf{D}$ \\
\hline $\mathrm{E}_{1}$ & $\mathrm{~b}_{2}$ & $\mathrm{~b}_{1}$ & $\mathrm{~b}_{1}$ & $\mathrm{c}_{2}$ \\
\hline $\mathrm{E}_{2}$ & $\mathrm{~b}_{2}$ & $\mathrm{~b}_{1}$ & $\mathrm{~b}_{3}$ & $\mathrm{c}_{2}$ \\
\hline $\mathrm{E}_{4}$ & $\mathrm{~b}_{2}$ & $\mathrm{~b}_{2}$ & $\mathrm{~b}_{3}$ & $\mathrm{c}_{1}$ \\
\hline $\mathrm{E}_{5}$ & $\mathrm{~b}_{3}$ & $\mathrm{~b}_{3}$ & $\mathrm{~b}_{3}$ & $\mathrm{c}_{1}$ \\
\hline
\end{tabular}

\begin{tabular}{|l|l|l|l|l|}
\hline $\mathrm{E}_{6}$ & $\mathrm{~b}_{2}$ & $\mathrm{~b}_{2}$ & $\mathrm{~b}_{2}$ & $\mathrm{c}_{2}$ \\
\hline $\mathrm{E}_{7}$ & $\mathrm{~b}_{2}$ & $\mathrm{~b}_{2}$ & $\mathrm{~b}_{2}$ & $\mathrm{c}_{1}$ \\
\hline $\mathrm{E}_{8}$ & $\mathrm{~b}_{1}$ & $\mathrm{~b}_{1}$ & $\mathrm{~b}_{1}$ & $\mathrm{c}_{2}$ \\
\hline $\mathrm{E}_{9}$ & $\mathrm{~b}_{2}$ & $\mathrm{~b}_{2}$ & $\mathrm{~b}_{3}$ & $\mathrm{c}_{1}$ \\
\hline $\mathrm{E}_{10}$ & $\mathrm{~b}_{2}$ & $\mathrm{~b}_{2}$ & $\mathrm{~b}_{2}$ & $\mathrm{c}_{2}$ \\
\hline $\mathrm{E}_{11}$ & $\mathrm{~b}_{3}$ & $\mathrm{~b}_{3}$ & $\mathrm{~b}_{3}$ & $\mathrm{c}_{1}$ \\
\hline $\mathrm{E}_{12}$ & $\mathrm{~b}_{2}$ & $\mathrm{~b}_{3}$ & $\mathrm{~b}_{1}$ & $\mathrm{c}_{1}$ \\
\hline $\mathrm{E}_{13}$ & $\mathrm{~b}_{2}$ & $\mathrm{~b}_{2}$ & $\mathrm{~b}_{2}$ & $\mathrm{c}_{2}$ \\
\hline $\mathrm{E}_{14}$ & $\mathrm{~b}_{3}$ & $\mathrm{~b}_{3}$ & $\mathrm{~b}_{3}$ & $\mathrm{c}_{1}$ \\
\hline $\mathrm{E}_{15}$ & $\mathrm{~b}_{1}$ & $\mathrm{~b}_{1}$ & $\mathrm{~b}_{1}$ & $\mathrm{c}_{2}$ \\
\hline $\mathrm{E}_{16}$ & $\mathrm{~b}_{1}$ & $\mathrm{~b}_{1}$ & $\mathrm{~b}_{1}$ & $\mathrm{c}_{2}$ \\
\hline $\mathrm{E}_{17}$ & $\mathrm{~b}_{3}$ & $\mathrm{~b}_{2}$ & $\mathrm{~b}_{2}$ & $\mathrm{c}_{1}$ \\
\hline $\mathrm{E}_{18}$ & $\mathrm{~b}_{2}$ & $\mathrm{~b}_{2}$ & $\mathrm{~b}_{3}$ & $\mathrm{c}_{2}$ \\
\hline
\end{tabular}

Upon analyzing table-3 we have the following result that is $\left(\mathrm{E}_{5}, \mathrm{E}_{11}, \mathrm{E}_{14}\right),\left(\mathrm{E}_{8}, \mathrm{E}_{15}, \mathrm{E}_{16}\right),\left(\mathrm{E}_{10}, \mathrm{E}_{13}\right)$, forms group and $\left(\mathrm{E}_{6}, \mathrm{E}_{7}\right)$ $\left(\mathrm{E}_{9}, \mathrm{E}_{9}, \mathrm{E}_{18}\right)$,ambiguous so we keep on record for each group and delete all records which gives ambiguous result so we have the new table appears as table- 4 given as follows

Reduced Table-4 from Table-3

\begin{tabular}{|l|l|l|l|l|}
\hline $\mathbf{E}$ & $\mathbf{a}_{2}$ & $\mathbf{a}_{3}$ & $\mathbf{a}_{4}$ & $\mathbf{D}$ \\
\hline $\mathrm{E}_{1}$ & $\mathrm{~b}_{2}$ & $\mathrm{~b}_{1}$ & $\mathrm{~b}_{1}$ & $\mathrm{c}_{2}$ \\
\hline $\mathrm{E}_{2}$ & $\mathrm{~b}_{2}$ & $\mathrm{~b}_{1}$ & $\mathrm{~b}_{3}$ & $\mathrm{c}_{2}$ \\
\hline $\mathrm{E}_{5}$ & $\mathrm{~b}_{3}$ & $\mathrm{~b}_{3}$ & $\mathrm{~b}_{3}$ & $\mathrm{c}_{1}$ \\
\hline $\mathrm{E}_{8}$ & $\mathrm{~b}_{1}$ & $\mathrm{~b}_{1}$ & $\mathrm{~b}_{1}$ & $\mathrm{c}_{2}$ \\
\hline $\mathrm{E}_{10}$ & $\mathrm{~b}_{2}$ & $\mathrm{~b}_{2}$ & $\mathrm{~b}_{2}$ & $\mathrm{c}_{2}$ \\
\hline $\mathrm{E}_{12}$ & $\mathrm{~b}_{2}$ & $\mathrm{~b}_{3}$ & $\mathrm{~b}_{1}$ & $\mathrm{c}_{1}$ \\
\hline $\mathrm{E}_{17}$ & $\mathrm{~b}_{3}$ & $\mathrm{~b}_{2}$ & $\mathrm{~b}_{2}$ & $\mathrm{c}_{1}$ \\
\hline
\end{tabular}

As we observe $\mathrm{E}_{8}$ and $\mathrm{E}_{10}$ has conditional attributes values different but giving same decision so we safely drop both for further classification .further reduction Table -4 is not possible.

From the table we are develop an algorithm is as follows

1. above average cases of $\mathrm{a}_{2}, \mathrm{a}_{4}$ and $\mathrm{a}_{3}$ giving significant result for negative case of followers for self declared God man

2. above average cases of $\mathrm{a}_{2}, \mathrm{a}_{4}$ and $\mathrm{a}_{3}$ provide a leads for negative followers for self declared god man

3. High or severe cases of $\mathrm{a}_{2}, \mathrm{a}_{4}$ and $\mathrm{a}_{3}$ leads to 
positive cases of followers for self declared god man

4. Average $\mathrm{a}_{2}, \mathrm{a}_{4}$ and, $\mathrm{a}_{3}$ not provided significance result for followers of self declared god man

5. Above average $a_{2}, a_{3}$ is significant average $a_{4}$ leads to positive or definite case of followers of self declared god man

6. High $\mathrm{a}_{2}, \mathrm{a}_{3}$ above average cases of, $\mathrm{a}_{4}$ leads to positive case of self declared god man

The above algorithm gives us a conclusion that 1) lack of education 2) to achieve goal in short period of time are root cause in the transformation of common people to become followers of self declared God man

Statistical validation I- To validate our findings we basically depends upon chi-square test for this purpose we take a survey by taking data regarding the positive cases and we are not focused on one particular areas to collect the data we approached several sources and gathered information and then apply chi square test to validate our claim. $\quad$ Chi square testExpected $15 \%, 10 \%, 15 \%, 20 \%, 30 \%, 15 \%$ and the Observed samples are $25,14,3445,62,20$ so totaling these we have total of 200 samples so expected numbers of samples per each day as follows $30,20,30,40,60,30$. We then apply chi square distribution to verify our result assuming that $\mathrm{H}_{0}$ is our hypothesis that is correct $\mathrm{H}_{1}$ as alternate hypothesis that is not correct , Then we expect sample in six cases as chi squared estimation formula is $\sum\left(\mathrm{O}_{\mathrm{i}}-\mathrm{E}_{\mathrm{i}}\right)^{2} / \mathrm{E}_{\mathrm{i}}$ where $\mathrm{i}=0,1,2,3,4,5$ so the calculated as follows

$\mathrm{X}^{2}=(25-30)^{2} / 30+(14-20)^{2} / 20+(34-30)^{2} / 30+(45-$

$40)^{2} / 40+(62-60)^{2} / 60+(20-30)^{2} / 30$

$X^{2}=25 / 20+36 / 20+16 / 30+25 / 40+4 / 60+100 / 30$

$=7.60$ the tabular values we have with degree of freedom 5 we get result 11.04. This result is well below the tabular values, this gives us to accept our claim.

Statistical validation II- Apply chi square test to validate our claim. For the second case as follows . Chi square test- Expected14\%,16\%,15.5\%,21\%,31\%,14\% and the samples are $26,18,34,43,61,20$. so totaling these we have total of 200 samples so expected numbers of samples per each day as follows $28,32,31,42,62,28$. We then apply chi square distribution to verify our result assuming that $\mathrm{H}_{0}$ is our hypothesis that is correct $\mathrm{H}_{1}$ as alternate hypothesis that is not correct , Then we expect sample in six cases as chi squared estimation formula is $\sum\left(\mathrm{O}_{\mathrm{i}}-\mathrm{E}_{\mathrm{i}}\right)^{2} / \mathrm{E}_{\mathrm{i}}$ where $\mathrm{i}=0,1,2,3,4,5$ so the calculated as follows 8.879 it is far below the tabular values 11.04 wit degrees of freedom 5 so we accept our claim.

\section{FUTURE WORK}

This idea can be extend to entertainment, Business logic development and in the Field of agriculture, Entertainment and Education.

\section{REFERENCES}

[1] Cios, K., W. Pedrycz and R. Swiniarski (1998). Data Mining Methods for Knowledge Discovery. Kluwer Academic

[2] Wolf, S., H. Oliver, S. Herbert and M. Michael (2000). Intelligent data mining for medical quality management

[3] Se-Ho, Ch., and P. Rockett (2002). The training of neural classifiers with condensed datasets. $S M C B$, 32(2),202-206.,

Setiono, R. (2000). Generating concise and accurate classification rules for breast cancer diagnosis. Artificial Intelligence in Medicine, 18(3), 205-219

[4] Cheeseman, P., and J. Stutz (1996). Bayesian classification (AutoClass): theory and results. In U.M.Fayyad

[5] Grzymala-Busse, J., Z. Pawlak, R. Slowinski and W. Ziarko (1999). Rough sets. Communications of the ACM

[6] Hassanien, A.E. (2003). Classification and feature selection of breast cancer data based on decision tree algorithm

[7] Parido, A., and P. Bonelli (1993). A new approach to fuzzy classifier systems. In Proceedings of the FifthInternational Conference on Genetic Algorithms. pp. 223-230

[8] Lin, T.Y., and N. Cercone (1997). Rough Sets and Data Mining. Kluwer Academic Publishers.Ning, S., H. Xiaohua, W. Ziarko and N. Cercone (1994). A generalized rough sets model. In Proceedings ofthe 3rd Pacific Rim International Conference on Artificial Intelligence, Vol. 431. Beijing, China. Int. Acad.Publishers. pp. 437-443.

[9] Pawlak, Z. (1991). Rough Sets-Theoretical Aspect of Reasoning about Data. Kluwer Academic Publishers.Pawlak, Z., J. Grzymala-Busse, R. Slowinski, W. Ziarko (1995). Rough sets. Communications of the ACM

[10] Renu Vashist Prof M.L Garg Rule Generation based on Reduct and Core :A rough set approach InternationalJournal of Computer Application(0975887) Vol 29 September -2011 Page 1-4

[11] Sujogya Mishra , shakthi Prasad mohanty,Sateesh Kumar Pradhan Radhanath Hota Parameters to find the cause of Global Terrorism using Rough Set Theory International Journal of Computer Applications (0975 - 8887) Volume 127 - No.14, October 2015 Page 4650

[12] Sujogya Mishra , shakthi Prasad mohanty,Sateesh Kumar Pradhan Radhanath . Importance of Location Classification using Rough Set Approach for the Development of Business Establishment International Journal of Computer Applications (0975 - 8887) International Journal of Computer Applications (0975 - 8887) Volume 119 - No.24, June 2015 